\title{
SOME OBSERVATIONS ON THE ROLE OF ALLERGY IN LEPROSY.
}

\author{
By T. F. Davey.
}

\section{INTRODUCTION.}

In chronic infections such as tuberculosis, syphilis, yaws, etc., the course of the disease is profoundly modified by the ability of the infective agent to act as an antigen and stimulate the hypersensitive state, and the importance of this in relation to pathology, clinical appearances, prognosis and treatment is generally accepted. Leprosy should be no exception in this respect, and the existence of allergic hypersensitiveness in leprosy has. indeed long been recognised, evidenced by the tuberculoid forms of the disease. 
The study of this aspect of leprosy is hampered by continued failure both to culture the bacillus with certainty in the laboratory and to discover an animal readily susceptible to infection. These limitations do not apply in the case of tuberculosis, and in recent years great advances have been made in our knowledge of the mechanısm of allergy in that disease. There are many similarities between M.Tuberculosis and its less toxic neighbour, M.leprae, obvious where morphology and staining reactions are concerned, apparent also in the forms of disease which the two mycobacteria produce and seen not least in the cutaneous manifestations of tuberculosis and leprosy. The relationship here cannot be accidental. In tuberculosis, sensitisation is the rule in all but a minority of cases, and although M.leprae appears to be of a lowlier antigenic order, there are reasons for believing that allergy in leprosy plays a role wider than that usually allotted to it. Although specific antibodies have not yet been demonstrated in leprosy, and any discussion of the subject must therefore be hypothetical, the analogy with tuberculosis is sufficiently close to warrant the conclusion that similar defence mechanisms are at work in the two diseases.

M.ieprae is of low pathogenicity. One of the striking features of leprosy is the capacity of the human body to harbour enormous numbers of M.leprae for many years with but little danger to life. This almost unique state of affairs permits of but one conclusion, namely, that the bacillus is essentially of feeble pathogenicity, its metabolic processes being tolerated by the host, and its presence arousing a basic response little more energetic than that evoked by many inert substances. Its toxicity is considerably less than that of M.tuberculosis, and the tolerance of the tissues to it is seen by the enormous bacillary multiplication which can occur in the body before disease symptoms drive a patient to seek medical advice. Two other properties of the bacillus can be deduced from clinical observation, (a) its ability to remain dormant for long periods, and (b) its tendency to die out after many years of residence in the human body.

Anergic leprosy (or pre-allergic leprosy). On the analogy of tuberculosis, it may be presumed that all clinical infections with M.leprae pass through an initial, non-allergic phase. During this phase, any reaction of the body is stimulated solely by the feebly pathogenic organism, and is correspondingly feeble, varying with individual resistance to infection and with the virulence of the infecting bacilli. It presumably takes the form of a simple round cell response at the site of infection in the skin, followed by phagocytic mononuclear cells which become the dominating 
feature. It is possible that the infection in resistant individuals may be aborted and disappear, but it is certain that in susceptible persons the tolerrated bacillus suffers no restraint, the phagocytic capacity of the macrophage response being incapable of halting it, and local spread, both directly and via the lymphatics, is soon followed by bacillary metastasis and the repetition of the same process elsewhere. The development of this chain of events is seen clearly in early lepromatous leprosy. It may be stated immediately that the writer does not consider lepromatous leprosy is a homogeneous form of the disease. In more advanced cases the clinical picture in many instances has been confused by a single or repeated allergic phase, but true anergic or pre-allergic leprosy is seen clinically in early lepromatous leprosy, characterised by insignificant lesions featured by infiltration, and unaccompanied by definite macules or marked nerve thickening. Such foci of infiltration may later develop into diffuse thickening and nodules. The duration of this phase is very variable. It is said to be about eight weeks in the human subject in the case of tuberculosis. In leprosy, as in tuberculosis, there must be a minimal latent period for the creation of allergy, but there appears to be no maximum. A patient suffering from leprosy may never pass beyond this phase, but in the opinion of the writer this is an uncommon event, sensitization occurring in the vast majority of cases and immediately confusing the picture. In many patients the first visible signs of infection coincide with the onset of sensitization, the pre-allergic phase being pre-clinical and thus rarely observed.

\section{Part I. Allergy as Seen in Tuberculoid Leprosy.}

Jadassohn and Lewandowsky's well-known dictum states that when bacteria are able to multiply without restraint within the organism, owing to absence of immunity, the organism responds with non-specific banal inflammation; but when bacteria or their products enter into reaction with antibodies, the result is tubercles or a tubercular structure. Hence when tuberculoid structures are seen it may be assumed that under the influence of antibodies the microbes are undergoing disintegration and are being eliminated in that site (Jadassohn 1914; Lewandowsky 1916).

This is seen typically in tuberculoid leprosy, and the characteristics of allergy in leprosy can therefore best be studied by reference to this form of the disease, the allergic nature of which is also confirmed by the consistently positive lepromin reaction.

CLINICAL COURSE OF THE TUBERCULOID MACULE.

It is not proposed to classify the various forms of tuberculoid 
leprosy, neither is any full description of tuberculoid leprosy called for. Excellent accounts have already appeared in the literature, notably by Wade (1934a, 1936, 1937, 1938) and Lowe (1936). We are concerned here with the development and progress of the tuberculoid macule, and a brief account from that standpoint is desirable.

A tuberculoid change may arise in an already existing leprosy lesion in the skin, when part or the whole of it exhibits increased activity to a varying degree. When activity is marked, it is usually accompanied by the appearance of new macules.

New tuberculoid macules either take the form of temporary, fading papules, or of more chronic spreading lesions which later regress. The usual story is as follows.

The macule begins as a small, well defined papule of varying elevation, hypopigmented in dark skins, and usually erythematous. It is commonly surrounded by a narrow zone of hypopigmentation. The papule enlarges by centrifugal spread and its elevation may increase at first. The process of enlargement is usually considerably aided by the appearance immediately adjacent to the original lesion of a succession of micropapules which follow an identical course and become confluent with it. In this way a small plaque is produced which continues to spread by the same process. In certain circumstances the macule may resolve while still at the papule stage. Beyond the advancing edge the hypopigmented zone may persist, while in its vicinity "Colonial macules" may arise, which by confluence with the parent macule produce irregularly shaped lesions which may finally grow to an enormous size. At an early stage in the development of the macule interference with sweat gland function and with sensation becomes apparent in it. Sooner or later, signs of spontaneous resolution appear. These may involve the macule as a whole, which ceases to spread, erythema disappears and the macule flattens and pigmentation returns, or more commonly, while the edge of the macule continues to spread, signs of resolution appear in its centre, which becomes depressed, and an annular lesion results. This may take a very chronic course. In the centre of the macule the skin may return almost to normal, pigmentation may return and sensation reappear. Activity in such cases is confirmed to the edge of the macule which slowly spreads, but finally the healing process predominates, activity is confined to isolated foci around the periphery of the lesion and these too ultimately disappear. There may be periods of incomplete healing followed by more extension before final resolution occurs. In this cycle of events every graduation is seen between the highly elevated erythematous lesions of major tuberculoid leprosy in reaction, which spread 
rapidly and resolve readily, and the chronic annular minor tuberculoid which may persist for years before finally resolving.

FACTORS RESPONSIBLE FOR THE TUBERCULOID LEPRIDE.

\section{(1) Role of the skin in allergy.}

The skin is an integral part of the reticulo-endothelial system and of supreme importance as an allergic defence organ. Urbach (1943a) states, "The skin produces antibodies more rapidly and in greater number than any other tissue," and this activity is due to the number of cells of the reticulo-endothelial system present in the dermis. It is particularly marked in tuberculosis. In leprosy ton, where the infective agent presumably enters the body through the skin, it is in the skin that the principal fight against the bacillus is staged in a sensitised individual.

(2) Primary sensitisation.

The allergic state can only follow an initial sensitising infection, and in tuberculoid leprosy it is to be presumed that an initial infection with M.Leprae results after a primary latent period in the creation of specific antibodies to the proteins of the bacillus, these being capable of combining with the antigen, the resultant antibody-antigen complex producing the characteristic allergic inflammation. The existence of complement-fixing antibodies has been demonstrated in tuberculosis (Freund and Opie, 1938). At the site of original infection, if this is still active, a tuberculoid macule will appear, but the change of reactability becomes a property of the entire skin.

It does not follow that on the onset of sensitisation antibody is forthwith elaborated by the entire skin. It is certainly produced locally wherever antigen is present, and by diffusion both locally and via the blood stream a certain amount must be deposited elsewhere. It is however not necessary for the entire skin to participate forthwith in this action, provided that it is subsequently able to do so at short notice on contact with the antigen. It is believed that the essential change on sensitisation is the endowment on the skin as a whole, and indeed on the entire reticuloendothelial system, of the ability to produce antibody locally on contact with the antigen at a greatly accelerated rate, so that a process which required weeks, months, or even years for its initial realisation can occur in days or even hours. Whatever concentration of antibody in the skin as a whole is achieved when sensitisation first occurs, this plays but a small part in subsequent events.

There is considerable evidence that in tuberculosis the antibody is essentially sessile, with but little ability to diffuse generally. To quote Sabin and Joyner (1938b), "It is our opinion that 
in the disease tuberculosis there is a mechanism of which some part at least is like an Arthus phenomenon; that in the disease the mechanism may be much more complex than is the reaction to a single protein, but that some of the difference may be due to a variation in the amount of antibody free in the circulation and the amount and kind of change in the cells. If it be not legitimate to consider the change in the sensitised cells of the tuberculous animal as due to antibodies, it is nevertheless due to the change in the cells themselves, probably induced by proteins set free from the infecting bacilli. That the cells are sensitised to the protein was shown by Rich and Lewis (1932). It was later shown by Moen (1936) that the cells from a tuberculous animal remained sensitive after several generations in cultures." In leprosy, Rodriguez (1938a) failed to obtain a significantly positive Prausnitz-Kustner reaction, a result in line with that usually found in tuberculosis. Urbach (1943b) claims that the presence of cellular antibodies has been demonstrated in the skin by means of the Urbach-Kolnigstein technique. Topley and Wilson (1946a), Urbach (1943c), Zinsser and Bayne Jones (1939) believe in the essential unity of constitution of antibodies, and if antibody is a globulin it must be selectively retained in the skin, though some diffusion appears inevitable.

(3) A toxic cause is not admitted, but a focus of living bacilli.

It has been suggested that tuberculides are due, not to the local action of M.tuberculosis, but to toxins derived from some distant focus. This view has been rejected by many workers (Montgomery 1935, Lewandowsky 1916, Guy 1923, Wile and Grauer 1935), who maintain that M.tuberculosis is itself responsible, negative findings being due to its rapid destruction. There can be no room for doubt that tuberculoid lesions in leprosy are produced by actual foci of M.leprae of exogenous or metastatic origin.

(4) Bacillary factors.

Virulence. The allergic response, awakened by the proteins of the bacillary body, does not of necessity depend on the actual virulence of the bacilli. At the same time, variation in the virulence of M.tuberculosis are well known, some authorities believing that tuberculides are produced by atenuated bacilli (Ormsby and Montgomery 1943). Muir (1946), doubts the existence of variations in the virulence of M.leprae. Variations in invasiveness however certainly occur.

The early lepromin response and the tuberculoid response. These are distinct but intimately related indications of the allergic state. The early lepromin reaction is an allergic response solely to 
the protein antigens of the. lepra bacillus, and is fully in line with the reaction to tuberculin (Dharmendra and Lowe, 1943, 1946). The tuberculoid response is of more complex nature. The following lable gives the percentage composition of M.tuberculosis together with the cellular reactions evoked by the separate fractions of the bacillus when injected alone. It is derived from Chargaff, Pangborn and Anderson (1931), Sabin (1938a), Sabin, Smithburn and Thomas (1938) and Sabin and Joyner 1938a).

\begin{tabular}{|c|c|c|c|}
\hline Constituent & $\begin{array}{l}\text { Perce } \\
\text { compc }\end{array}$ & $\begin{array}{l}\text { ntage } \\
\text { sition }\end{array}$ & $\begin{array}{l}\text { Cellular reaction induced by separate } \\
\text { fraction. }\end{array}$ \\
\hline Polysaccharide & $\underset{0.8^{*}}{\operatorname{human}}$ & $\begin{array}{r}\text { bovine } \\
1.02\end{array}$ & \multirow{5}{*}{$\begin{array}{l}\text { Exudate of neutrophil leucocytes from } \\
\text { the blood into the tissues. } \\
\text { As polysaccharidies, also stimulated } \\
\text { phagocytic mononuclear cells. } \\
\text { Tubercles developed with epithelioid } \\
\text { cells and Langhans giant cells, also } \\
\text { lymphocytes. } \\
\text { Multiplication of imonocytes and their } \\
\text { fusion to foreign body giant cells. } \\
\text { Monocytes, macrophages, epithelioid } \\
\text { cells, tubercles, giant cells of both } \\
\text { types, lymphocytes. }\end{array}$} \\
\hline Total lipins & 23.78 & 15.26 & \\
\hline $\begin{array}{l}\text { Phosphatide } \\
\text { fraction }\end{array}$ & 6.54 & 2.26 & \\
\hline $\begin{array}{l}\text { Waxes, alcohols } \\
\text { hydroxy acids }\end{array}$ & $1 \% .23$ & 12.98 & \\
\hline Proteins. & 75.01 & $\$ 4.71$ & \\
\hline
\end{tabular}

The reactions were much more intense in tuberculous than in normal animals.

Both the various proteins and the phosphatide thus actively participate in producing the tuberculoid response. The polysaccharide also cannot be excluded. Its ability to act as a hapten and unite with existing antibody has been proved, even if it is unable to stimulate the production of antibody. The tuberculoid response iri naiural infections is thus a composite response produced by various constituents of the bacillus when this is introduced into a sensitised medium. The protein antigen appears to be the specific excitant, and when injected alone is rapidly fixed, the resultant inflammatory response rising to a maximum within 48 hours and then dispersing. When actual bacilli are concerned, the protein antigen is still the excitant, but the response persists as bacilli continue to exist, their fixation being a gradual process, the whole organism being concerned in the tuberculoid response. Sabin and Joyner (1938b) have demonstrated that the phosphatide fraction greatly enhances the action of the protein.

The tuberculoid response is designed first to localise and then eradicate the infection. Its sterilising influence varies very considerably in effectiveness. It is of interest to note the work of Joyner and Sabin (1938) in regard to the localising effect of the tuberculoid response. They found that if vital staining dyes are injected into the dermis of tuberculous and normal animals, the degree of dispersion of stained cells is far less in tuberculoid than 
in normal animals. The hypersensitive state thus appears to hinder the dispersion of cells and probably has the same effect on bacilli, so that the localisation of the bacilli may actually assist in the production of the local resjonse with greater speed than normally.

IMPLICATIONS OF THE PROGRESS OF THE TUBERCLLOID MACULE,

The spreadling of a macule, followed by its resolution after a matter of wceks or months can arise only from two possible causes. (a) The bacilli after early activity, die nut sjontaneously. This is not in accord with all available knowledge of the habits of M.leprae, which indicates the ability of the bacillus to maintain itself for years. (b) $\Lambda \mathrm{fter}$ an initial delay, an effective response is in fact createrl, and later overtakes and overwhelms the bacilli.

This local time lag is a logical necessity. It may be of brief duration, but during the interval bacilli though they may be few in number are able to spread and gain a start on the response. At its conclusion the effective response becomes visible as the tuberculoid papule described above. A distinction must be drawn between this local latent period and the primary latent period required before sensitisation can occur in a previously insensitised individual. J)uring the primary latent period, no tuberculoid macule whatever is possible. There can only be a tuberculoid macule when the person is sensitised and the power to create antibodies has been conferred on the skin. The local latent period is the time required for the local resjonse to a subsequent focus of infection to become effective.

The cause of this local latent period is of considerable interest. It may confidently be asserted that the arrival of free bacillary antigen in a skin previously cndowed with antihodies, or at least able to produce a required concentration as short notice, will result within 24 hours in a detcctalle response. Failure to obtain a response means that an essential clement in the reaction is lacking. We are concerned here with three variables, the antigen, the antibody, and the resjonse evoled by the antigen-antibody complex, any one, or any combination of which may be at fault. It is instructive to consider the possible alternatives.

(1) Delay in the stimulation of the effective allergic inflammatory response.

The most effective bacteriological element in the tuberculoid response is said to be the young cjithelioid cell (Nolasco 1940). During the time required for the development of such cells in sufficient numbers, bacilli will have an opportunity to spread. In his histological studies of the Mitsuda Reaction, Rodriguez (1938b) and Nolasco (1940) found epithelioid cells in evidence by the 10th 
day, distinct tubercles being apparent by the end of the second week. Working with tuberculosis, Sabin (1938b) found that small tubercles developed on the peritoneum of the rabbit four days after the injection of the proteins of the tubercle bacillus. Here then is a definite cause for the local time lag, but it is not the only one. If a time lag of several days is required before an effective response can be mobilised behind advancing bacilli, and this is the only factor operating, there is no reason why the response should ever catch up on the bacilli, so that although the macule will certainly spread, there is no reason why it should ever cease to spread.

On the other hand, if the other two variables are at maximum efficiency, and the bacilli are rapidly fixed by an adequate concentration of antibody, they are immediately inhibited from spreading, and any subsequent delay in the mobilisation of the inflammatory response for a matter of days will not account for the continued spread of a macule over a period of weeks and months. Thus whether bacilli are fixed rapidly or not, the delay in the mobilisation of an EFFECTIVE response is not the only factor operating. (2) Faubts in the antigen (i.e. initial deficiency of antigen).

Although it is true that a minimal threshold amount of antigen is necessary to produce an allergic response in a sensitised individual, this amount is generally extremely minute. The real question with which we are concerned is whether the free bacillus can act as an antigen, or whether its preliminary breakdown to release the contained proteins is required. In this connection the work of Dharmendra and Lowe (1943) is of special interest. They show that the antigen of the lepra bacillus is the protein of the bacillary body, probably the nucleoprotein. The inoculation of the purified antigen in a sensitised subject does indeed induce the tuberculin type of reaction, whereas the crude antigen employed in the Mitsuda Reaction, consisting essentially of a suspension of killed lepra bacilli evokes only a mild early response but a marked delayed response, maximal in 3-4 weeks. Dharmendra and Lowe attribute this to the slow breakdown of the lepra bacillus when introduced into the skin, the gradual liberation of the effective somatic antigen causing the delayed response, also its nodular character. This implies that the actual release of the free bacillary protein is a necessary preliminary to the allergic response. On the other hand, in his initial experiments, Koch (1891) actually injected suspensions of living tubercle bacilli into the skin of sensitised animals, and secured a visible response within 24 hours. Koch's experiments can only be explained on the assumption that the tubercle bacillus is destroyed extremely quickly, thus releasing the antigen, or else that the whole bacterial 
cell of the tubercle bacillus is itself able to act in toto as does the specific protein antigen. If the former assumption is correct, one would not expect so wide a divergence between the tubercle bacillus and M.leprae in the time necessary for their disintegration, especially as the superior acid-fastness of M.tuberculosis would suggest the possibility of a higher resistance to destruction on its part.

The work of Rodriguez demonstrates that in a positive Mitsula Reaction the development of the tuberculoid response occurs simultaneously with that of the visible nodule in the skin, and obviously accounts for it. Sabin's work indicates that more than the protein antigen is involved in the production of the tuberculoid response, the whole bacillus being concerned. It is a well known finding that if lepra bacilli can be demonstrated at all in a tuberculoil lesion, they will be found at its spreading edge in far greater frequency than elsewhere. The mere fixation of free bacillary antigen will not explain this. Either the complete bacilli are themselves fixed, anchored, and then destroyed by the tuberculoid response in the macule, or else the tuberculoid response, initiated by the antigen-antibody complex (where the protein of the bacillus is the antigen) is itself able to attack and destroy free bacilli quite apart from the necessity for their preliminary fixation by antibody.

As already mentioned, the tuberculoid response sometimes takes the form of papules which closely resemble the positive Mitsuda Reaction, in that they appear over a period of a few weeks, rise to a maximum and then resolve with but little spread. In these cases which are not rare in Nigeria, and have been described by Wade (1934b, 1939a), the essential difference from the Mitsuda Reaction is that whereas the latter is produced by killed bacilli, the tuberculoid papules occurring during a natural infection are produced by living bacilli, and it is apparent that these are eithe: destroyed with unusual rapidity, or else that they are themselves anchored in the skin and prevented from dispersing. We may say then that although the protein is the essential antigen of the lepra bacillus in initiating the allergic response, the whole bacillus is concerned in the development of the tuberculoid response in natural infections, and either the whole bacillus is able to act in toto as does its protein, and in consequence is fixed and anchored in the skin by antibody, or else the allergic inflammation is able to attack and destroy free bacilli with rapidity.

In any case, bacillary factors alone will not account for the spread and subsequent resolution of the tuberculoid macule. Given a uniform and effective concentration of antibodies in the skin, if bacilli are fixed completely, the macule cannot spread. If preliminary bacillary disintegration is necessary, there is no reason 
for its ever ceasing to spread, apart from the spontaneous dying out of the bacilli. This result will not be influenced if in addition the delay in developing the tuberculoid response is allowed for. Thus although bacillary factors, and the delay in development of the tuberculoid response will explain the spread of a macule, they will not explain its resolution, and in this the antibody factor must be involved.

(3) Deficiency of antibody.

We are dealing only with a sensitised individual, in whose skin antibody appeared during the initial infection, and the ability to synthesise antibodies persists. If a subsequent focus of bacilli arrives in the skin while its antibody content is still adequate, any visible lesion must take the form of a tuberculoid papule which rapidly subsides. Any initial delay in the release of antigen from the bacilli will merely result in a spreading lesion. At this stage, endogenous spread of infection is indeed unlikely, in view of the effective response at the initial lesion, provided that it is situated in the skin. Superinfection is of course possible.

The spreading and subsequently resolving lesions characteristic of clinical tuberculoid leprosy cannot be accounted for on the supposition that pre-existing antibodies alone are involved. A concentration of antibudy which permits a bacillary focus to spread cannot later encompass its resolution, and it follows that to achieve this fresh antibody must be synthesised. Clinical tuberculoid leprosy arises when the original concentration of antibody in the skin has fallen to an ineffective level. This is the necessary precursor of the spreading tubercloid macule. The fall in concentration could doubtless occur from the gradual decline in concentration and reactability wh:ch would follow the complete elimination of the original infection, when the new lesion would indicate an exogenous infection. It is much more likely that in most cases of tuberculoid leprosy, other factors have combined to depress the response before the original infection is completely eliminated, and bacillary multiplication is thereby allowed to occur. In this connection it is of interest to notice that in tuberculous individuals, an attack of measles may lead to a negative tuberculin reaction, and that measles is a common preliminary to the eruption of a tuberculide (Morris 1903). We have here comparable circumstances in tuberculosis.

The appearance of the tuberculoid lesion indicates that the response is once more at an effective level, and the new synthesis of antibody must have accounted for this. As will be shown later this synthesis occurs mainly at the site of the tuberculoid macule, and it follows that in a sensitised individual the presence of the bacillus results in the local synthesis of antibody. A certain 
time will be required for this, even though it may be brief, and this is probably the most important factor in producing the initial delay in the mubilisation of the response. It is thus possible to trace the local time lag to three causes, (a) the time required for the development of macrophages into epithelioid cells, (b) the possible need for the preliminary breakdown of the bacillus, (c) the time required for the resynthesis of antibody.

As the macule enlarges, what we are actually observing is the spread of the response as this reaches an effective level over a widening area, not the actual advance of the bacilli responsible for it. In the macule bacilli are rapidly destroyed, hence the frequency of the negative bacteriological test. The foremost bacilli are however located just ahead of the macule by the small distance they are able to traverse during the time lag before the local effective response is mobilised.

Where primary sensitisation occurs in an individual in whose skin bacilli have already spread over an appreciable area, we would expect the appearance of a tuberculoid lesion, not in the form of a small papule, but of a size equal to the extent of bacillary spread up to the time sensitisation occurred. The same applies to secondary lesions where these follow a loss of sensitisation and this is only regained some time after the secondary foci arrive in the skin.

Sooner or later the response gains on the advancing bacilli, the time lag is made up and the infection ultimately overwhelmed. Provided the local synthesis of antibodies is maintained at an effective concentration, it is apparent that the advancing bacilli are confronted by an increasing antagonistic medium in the skin ahead of them, for by diffusion both directly and by blood spread its antibody content must rise. Urbach (1943d) maintains that the presence of antibody inhibits the multiplication of bacilli. Even apart from this, when the antibody content of the skin around the macule reaches a reactive level, fixation of bacilli will occur, with a resultant visible response. To the eye this may be scarcely distinguished from the adjacent spreading macule which will appear to enlarge at a faster rate before finally coming to a standstill.

The narrow flat (or almost flat) zone of depigmentation which frequently encircles the tuberculoid macule in a dark skin may bear some relationship to this question. The allergic response is variable. It does not offer an "all or none" law. This zone probably exhibits the mild response produced by a relative concentration of antigen and antibody only just above the threshold value for reactivity. This could arise in the initial stage of a macule from the union of some of the bacillary antigen present 
with pre-existing antibody in the skin, when the response, though visible, would evidence its ineffectiveness by the continued spread of the macule, and final resolution would depend on the creation of new antibody. With the macule spreading, a similar state of affairs could continue in the skin immediately around the advancing edge. Its presence even later may arise from the union of antigen with newly deposited antibody in the skin around the macule, and would indicate the impending collapse of the infection locally. The eye only notices gross changes, but when these are sufficient to be noticed, the width of this zone may very well indicate the extent of penetration of the bacilli beyond the advancing tuberculoid response. In this connection a comment by Lowe (1937) is of interest. "In the outer depigmented zone of the annular macule, bacilli are frequently found, possibly more frequently than in the intermediate thick zone." (Sce also Wade 1934c.)

With the destruction of bacilli locally and the consequent disappearance of the antigen, the cellular infiltration disperses and a spreading zone of healing is formed.

\section{SITE OF SYNTILSIS OF ANTIBODY.}

The new concentration of antibody must be synthesised by the reticulo-endothelial system, and particularly the skin, either as a whole, or else locally. In the former case, the rise in concentration would occur everywhere as the entire dermis participated in its production. The effect of this should be felt on all tuberculoid lesions, regardless of their site, and should be followed by a simultaneous tendency to resolve. There is no doubt that sometimes there is a general tendency to resolution, but more frequently one macule resolves while another spreads. This is the experience of the writer, and there is abundant confirmation in the literature. Wade (1940), for example, states "Local variations of the process, retrogression of some lesions while others progress and new ones appear, is a common phenomenon in any variety of neural leprosy." These local variations lead to the conclusion that antibody, essentially sessile, is stimulated at the site of the tuberculoid macule by the presence of the bacillus.

There is much other evidence that antibody can be stimulated locally in the skin :

1. The appearance of focal reactions to injections of lepromin indicates that other foci of infection are in a different allergic state from the rest of the skin.

2. Hayashi (1933) found that the lepromin test was more marked in macules than in normal skin, especially in tuberculoid macules, the elevated borders of which reacted most strongly. 
This difference was specific, and was not seen in tuberculin tests in the same individuals.

3. The writer has found considerable variation between the intensity of the early lepromin reaction when carried out in macules and that carried out in normal skin in the same individual at the same time.

4. Urbach (1943) proved the production locally of antibodies in the skin which did not enter the blood stream to any marked extent.

5. Martenstein (see Urbach 1943) showed the production of antibodies in the skin which were not found till later in the serum.

6. Localised lepra reaction whether in skin or nerve is best explained by the local creation of antibodies.

7. When two spreading tuberculoid macules meet, the inflammatory process is stayed. The macules do not overlap, and hence bacilli able to advance through normal skin at the edge of one macule find themselves halted when meeting another macule. The antibody concentration is presumably higher here than in normal skin.

8. When healing occurs in a macule, the skin in the healed area is often insensitive to lepromin. It has been suggested that this is due to a large excess of antibody. If so this must have been created locally, as the same conditions need not apply to other macules present at the same time.

9. Topley and Wilson (1946) quotes the work of Hartley (1940) and DeGara and Angevine (1943) as evidence in favour of the local production of antibody in the skin. (See also Cannon and Sullivan, 1932).

FACTORS DETERMINING THE CLINICAL APPEARANCES.

(1) Variations in the intensity of allergy.

Clinically, great variation exists in the intensity of the response between one individual and another, and in one individual at different times. It is customary to classify tuberculoid macules as "Major" or "Minor," but in reality every conceivable gradation is seen between a chronic almost inactive, slightly elevated lesion, and the acute erythematous major tuberculoid macule in reaction. The visible macule is produced by the cellular response, and its intensity depends on (a) the depth of skin involved, (b) bacillary factors, and (c) personal factors.

(a) The depth of skin invalved. In major tuberculoid macules the lower levels of the dermis are involved, sometimes even the subcutanous tissue. It has been shown that bacilli must have preceded the response, and must themselves have penetrated these 
levels, or must have been deposited there in the first place. The appearance of colonial macules indicates the passage of bacilli along the lower lymphatic channels of the dermis. It is thus probable that as a rule the major tuberculoid macule occurs when bacilli have disseminated themselves locally throughout the thickness of the dermis and are hence already fairly numerous, though their rapid destruction by the massive response may yield a negative bacteriological test. This is in line with the clinical fact that major tuberculoid macules are frequently multiple.

(b) Bacillary factors. In both major and minor tuberculoid cases the degree of allergic inflammation is often enormous compared with the number of invading bacilli that can be detected. At the same time a bacteriologically positive minor tuberculoid lesion is very rare, whereas it is common in major tuberculoid lesions.

Considerable light on the mechanism involved in determining the degree of response is thrown by experimental studies of the effect on precipitation of varying concentrations of antigen and antibody in vitro. Important work has been done on this subject (Heidelberger and Kendall, 1935, 1936) and has demonstrated where precipitating antibodies are concerned that :

(i) A minimal concentration of both antigen and antibody is required for precipitation to occur.

(ii) Precipitation can occur over a considerable range of RELATIVE concentrations of antigen and antibody.

(iii) Precipitation rises to a maximum when optimum RELATIVE concentrations are attained.

(iv) Excess of either antigen or antibody actually inhibits precipitation, the effect of excess antigen being more marked than excess antibody.

If the local allergic response is based on a reaction of this nature, as is probable, the influence of bacillary concentration in the tissues on the degree of response is obvious, and clinical appearances actually support the conclusions which follow. Small amounts of antigen, combining with small amounts of antibody may be expected to lead to minor tuberculoid macules, the union of larger amounts leading to major tuberculoid macules. It is a fact that small single lesions are usually of the minor variety. The more opportunity bacilli have to multiply before the effective response is mobilised, the greater is the likelihood of major tuberculoid lesions.

(c) Personal factors. These are probably the most important of all. Some people are capable of being, sensitised to a highe level than others, and respond to a given infection with greate: 
violence and speed. This has its advantages in the prospect of the more rapid control of the infection, but has its disadvantages in that marked bacterial allergic reactions tend to cause toxaemia and impose a strain on the organism (Rowe 1937, Bray 1937, Pottenger 1934, Cummins 1935). The influence of secondary factors, climate, nutrition, secondary infections, psychological factors may individually be insignificant, but acting together may make all the difference between an effective and an ineffective response.

The great variation in the intensity of the allergic response in leprosy is closely parallelled in experimental work on allergy Freund and Opie, and others, has proved conclusively that allergy obeys no "all or none" law, but that every grade of response from slight to intense can be produced in a given animal by varying products and fractions of the tubercle bacillus, depending also on the amount of the antigen, the route of its administration, its relation to previous infection, whether in single or repeated doses, and so on. The histological picture varies in the same way. A tuberculoid structure is typical of moderate sensitisation, with the addition of necrosis when intense, while mild degrees of sensitisation are characterised simply by an increase of phagocytic mononuclear cells in the dermis and their development into epithelioid cells. The presence of epithelioid cells is thus the essential change, and even this may vary in degree. Sabin and Joyner (1938a) state, "It seems justifiable to stress the fact that an increase in monocytes and epithelioid colls accompanies the phenomenon of sensitisation, and that in some way the phagocytic mononuclear cells, specifically monocytes and their derivatives, epithelioid cells, play a definite role in the mechanism that sets up sensitisation."

(2) The Timing of Primary Sensitisation.

Urbach (1943f) states, "Infectious agents may not begin their allergising influence until they have existed in the body for some time." This is certainly true of leprosy and is an important factor in determining clinical appearances. A delay in sensitisation means a corresponding increase in the number of bacilli with which the body has to cope, and an increased likelihood of metastasis, and also the need for a more violent response if the infection is to be overwhelmed.

\section{(3) Superinfection.}

Individuals suffering from clinical leprosy have thereby betrayed their susceptibility to infection, and all too frequently live in conditions where continued contact with the lepra bacillus is likely to be a potent factor in initiating new lesions. 
(4) Drugs.

The influence of drugs such as potassium iodide and arsphenamine derivatives on clinical appearances in leprosy is profound. Arsenicals appear to exert a metallergic action and can stimulate the allergic state. The action of potassium iodide is more suspect.

\section{PERSISTENCE OF THE ALLERGIC STATE.}

Although when once developed, sensitisation is usually persistent, it is not necessarily permanent. Hypersensitivity to tuberculin may for example be lost during measles, whooping cough, meningitis, typhoid and other infections, also during vaccination, also in cachexia and anaemia, but also in acute fulminating tuberculosis, very late tuberculosis, and in completely healed lesions. Thus the advance of the specific infection itself to an overwhelming degree, other serious infections, or the depression of the vitality of the body, can all desensitise the skin in tuberculin. This is not surprising. Referring again to the work of Heidelberger and Kendall (1935) it will be noticed that with a heavy excess of antigen, precipitation is actually inhibited in vitro. It may therefore be expected that if the allergic response is unable to hold the bacilli in check and these continue to multiply, a point is reached when the allergic response is inhibited. Thus in leprosy, Rogers and Muir (1946) noted that during typhoid, leprous macules faded. Clinical instances of loss of sensitivity in leprosy are as follows:

\section{(1) Recurrence in previons tuberculoid lesions.}

Recurrence can occur at the site of previous and apparently healed tuberculoid macules after an interval of months, maybe years. If the recurrence is of tuberculoid nature the new lesions usually follow a benign course and take the form of papules which appear at the edge of the previous lesions and spread outwards. There is little tendency to invade the site of the previous lesion. We may presume that although apparently fully resolved to the naked eye, one or two bacilli persisted at the edge of the old lesion, and remained dormant. A subsequent decline in immunity permitted the multiplication of these bacilli, until increasing antigen again stimulated the tuberculoid response.

\section{(2) Partial resolution followed by more spread.}

In major tuberculoid lesions the massive response usually proceeds to its conclusion without interruption. Minor tuberculoid lesions sometimes present a variety of appearances which can only be explained on the basis of partial resolution followed by more spread. The minor tuberculoid response is at a lower level than 
the major response, and consequently nearer to the threshold of effectiveness. One would expect fluctuations in sensitivity to have a more noticeable effect at this lower level.

In both these cases, the temporary depression of the response is followed by its resurgence.

\section{(3) The degeneration of tuberculoid cases to the lepromatous type.}

There seems little doubt that in suitable circumstances loss of sensitivity may occur which persists. A loss of sensitivity means a return to anergic conditions, when the bacillus can proceed to multiply. With increasing antigen, a higher concentration of antibody will be needed to hold the infection in check, and the longer this is delayed, the greater will be the amount required. There is no doubt that bacillaemia is an extremely powerf ul stimulant of the allergic response, but if sensitivity is seriously depressed, even this may not suffice to reawaken it. One is impressed by the number of cases exhibiting recent lepromatous macules who give a history of an initial macule, the site of which still gives strong evidence of its allergic nature in the shape of clear definition, anidrosis and loss of sensation.

lt must be emphasised that although allergy exhibits many grades, there is a threshold level for effectiveness. Above this level it will achieve its object. Below it, it is unable to hold the bacillus in cherk, and multiplying bacilli may later inhibit even the partial response, though this may return, either from the stimulus of bacillaemia, or by increased vitality on the part of the host. The threshold level varies with the amount of antigen present, increasing antigen demanding ever higher levels of response if bacilli are to be checked.

There is ample evidence of fluctuations of allergy in tuberculosis. Thus Sabin (quoted by Urbach 1943) says, "Clinical experience shows that skin allergy fluctuates widely in man in tuberculosis individuals and is not necessarily related to the clinical outcome." Freund and Opie (1938) state, "In a tuberculous infection, the intensity of sensitisation diminishes and disappears with advancing disease, and with fatal infections sensitisation is usually absent during a considerable period before death. With tuberculosis in immunised animals that pursues a favourable course, sensitisation usually disappears, but may reappear in waves during the course of recovery. It is probable that desensitisation by excess of antigen formed during the progress of the infection has a part in this phenomenon."

In leprosy, the question as to whether tuberculoid cases can revert to lepromatous is a vexed one, but there seems to be no essential reason why they should be incapable of the change. The 
tuberculoid response is lost with difficulty, but the clinical indications are that this can occur. Examples of the change with histological evidence, are presented in the literature (Nolasco 1941).

\section{ALLERGY AND IMMUNITY.}

While allergy is certainly not equivalent to immunity, Topley and Wilson (1946) believe them to be related, different more quantitatively than in essential character. Rich (1941), on the other hand working with tuberculosis maintains that they are distinct and separate states of the organism.

In leprosy the healed centre of a tuberculoid macule is particularly resistant to reinfection. This is evidenced by the fact that in recurrence, spread continues outwards, not towards the centre of the macule. Thus a locally effective allergic response has imparted a degree of resistance to that tissue. It is probable that antibodies are present in excess in the healed area for a considerable time. The lepromin test here may be negative. The immunity is however only partial and may be broken down by a marked excess of antigen. Epstein (1940) demonstrated the existence of specific acquired local resistance following specific sensitisation. Wade (1934b, 1939b) describes cases in which the local immunity was broken down.

\section{SUMMARY :}

THE CHARACTERISATION OF ALLERGY IN TUBERCULOID LEPROSY.

1. The lepra bacillus is of feeble pathogenicity, but is able to act as an antigen and stimulate the specific tuberculoid response $o v \in r$ a wide range of concentration of the antigen.

2. An effective degree of sensitisation is evidenced by (a) a tuberculoid histology and (b) a positive reaction to lepromin, both early and delayed.

3. A primary latent period, the length of which is variable is required to initiate the hypersensitive state.

4. There are two elements concerned in clinical tuberculoid leprosy, (a) a primary focus of infection which sensitises and leads to the production of antibodies. This may be the only infective focus seen. (b) Secondary foci of exogenous or metastatic origin.

5. The essential change on sensitisation is the ability conferred on sensitised tissue as a whole to produce locally at a greatly accelerated rate an effective concentration of antibody in response to the presence of bacilli. The antibody is apparently mainly sessile, but some diffusion is probable.

6. The appearance of secondary spreading foci indicates a previous fall in the antibody content of the skin to an ineffective level, caused by a decline in sensitivity. During this phase bacilli 
are able to multiply and spread. The resolution of these foci follows the resurgence of sensitivity to an effective level, accompanied by the synthesis of fresh antibody, the exact clinical appearances depending on the time taken for the response to return.

7. The tuberculoid macule follows the return of sensitivity, and spreads as this reaches an effective level over a widening area.

8. The effect of the response is to localise the infection and fix it in the sensitised tissue.

9. The response is not an "all or none" response, but varies widely in intensity, depending on the amount of antigen and on personal idiosyncracy. Although hypersensitiveness exhibits many grades, there is a threshold level for effectiveness which varies with the amount of antigen involved, increasing antigen demanding higher levels of response if advancing and multiplying bacilli are to be checked.

10. The response though persistent is not of necessity permanent, it may be intermittant, and it may be lost. Its permanence and its effectiveness are influenced by the degree of vitality of the body.

11. Allergy is not equivalent to immunity, but a successful allergic response imparts a degree of local immunity as well as destroying the bacillus.

In Part II it is proposed to discuss these characteristics of allergy in relation to the other clinical forms of leprosy, to nerve involvement, and to lepra reaction.

My thanks are due to the Honourable the Director of Medical Services, Nigeria, for permission to publish.

\section{REFERENCES.}

BRAY, G. (1937). Recent Advances in Allergy, Churchill, London. 422. Cannon, P. R. and Sullivan, F. L. (1932). Proc. Sioc. Exp. Biol. N.Y. 29, 517 .

Chargaff, E., Pangborn, M.C. and Anderson, R. J. (1931). J. Biol. Chem. $61,45$.

Cummins, S. L. (1935). Bul. Int. Union aguinst Tub. 12, 234.

DeGara, P. F. and Angevine, D. M. (1943). J. Exp. Med. 78, 27.

Dharmendra and LoWe, J. (1943). Lep. in India 15, 82.

$$
\text { (1946). Lep. Rev. 17, } 9 .
$$

Epstein, S. (1940). J. Invest. Derimat. 3, 223.

Freund, J. and OpIE, E. L. (1938). J. Exp. Med. 68, 296.

GuY (1923). Arch. Derm. and Syph. 8, 754.

Hartley, G. (1940). J. Inf. Dis. 66, 44.

HAYASHI, F. (1933). Int. J. Lep. I, 34.

Heidelberger, M. and Kendall, F. E. (1935). J. Exp. Med. 61, 559,

(1936). I bid 62, 467, 697.

Jadassohn, J. (1914). Arch. f. Derm. u. Syph. I19, 10.

JoYNER, A. L. and SABIN, F. R. (1938). J. Exp. Med. 68, 325.

Kock, R. (1891). Dtsch. Med. Wsch. 101, quoted by Topley and Wilson (1946) 1161. 
Liwnniowskix, IF, (1910). Die Tuberk. der /laut. Berlin, quoted by Urbach (1943) Allergy.

Lowe, J. (1930). Lep. in Ind. 8, 97.

(1910). Arch. Derm. and Syph. 123, 1.

(1937). Int. I. Lep. 5, 190.

Martenstilin, H.. quoted by Urlach, E. (1943) Allergy, 794.

Moen, J. K. (1930). I. Exp. Med. 64, 943.

Montgomeriy, H. (1935). Ned. Cilin. N. Amer., Mayo Clinic Number, 011.

Morris (1903). Dis. of Skin, 422, quoted by Ormsby and Montgomery (1943) 870 .

Muir, E. (1946). Lep. Rer. 17, 5.

Nol_sico, J. C. (1940). Int. J. Lep. 8, 293.

Ormsiy, (O) and Montgomiry, H. (1943). Dis. of Skin, London, Henry Kimpton.

Rich, A. K. (1941). Physiol. Rei'. 21, 70.

Rich, A. R. and Lew1s, M. R. (1932). Bul. John Hopkins Hosp. I, 115.

Ronriciuez, J. N. (1933). Int. .I. Lep. 6, (a) 19, (b) 20.

Rowe, S. (1937). Clinical Allergy', Bailliere 'Tyndall and Cox, 431.

S^rin, F. R. (1938). J. Exp. Med. 68, (a)837, (1)842, (c) quoted by Urbach, E. Allergy (1943) 24.

SAmin, F. R. and JoYNer, A. L. (1938). J. Lixp. Med. 68, (a) 853, (b) 671.

Sinisn, I. R., Joyner, A. L. and Smithisurn, K. (¿. (1938). J. Li.rp. Med. $68,503$.

Simin, K. K., Smithisurn, K. (: and Thomss, R. M. (1930). J. Exp. Med. 62, 751, 771 .

Smithisurn, K. (. and Snimin, F. R. (1938). J. Exp. Med. 68, 041.

Topley, W. W: C. and Wilson, G. S. (1940). Principles of Bacteriology and Immunity. London, (a)252, (b) 1132.

Urinch, E. (1943). Allergy. Grune and Stratton, New York (a)793-4, (b)180, (c) $166,(d) 508$ (e) 794 (f) 163 .

WAlle, H. W. (1934) Int. I. Lep. 2, (a)7, (1)279, (c)29.

(1930) Ibid 4, 4()9.

(1937) Ibid 5, 285, 437.

(1938) Ibid 6, 119.

(1939) lbid 7, (a) 330, (1) 338.

(1940) Ibid 8, 320.

Zinsser, H. and BAyne Jones, S. (1939). A Textloook of Bacteriology, New York. 